\title{
GÊNERO, DIVERSIDADE SEXUAL, CIÊNCIA E TECNOLOGIA: \\ A ESCOLA COMO AGENTE DE MUDANÇAS ${ }^{1}$
}

\section{GENDER, SEXUAL DIVERSITY, SCIENCE AND TECHNOLOGY: THE SCHOOL AS AGENT OF CHANGES}

\author{
Tânia Rosa F. Cascaes ${ }^{2}$ \\ Tatiana de Souza ${ }^{3}$ \\ Marilia Gomes de Carvalho ${ }^{4}$
}

\begin{abstract}
RESUMO
O presente artigo tece considerações acerca da temática do módulo: Gênero, Diversidade Sexual, Ciência e Tecnologia, e descreve a atuação dos grupos de pesquisa GETEC-UTFPR - Relações de Gênero e Tecnologia - Universidade Tecnológica Federal do Paraná e REGEDI-UFPR - Relações de Gênero e Diversidade Sexual 1- Universidade Federal do Paraná/setor Litoral. Este trabalho, direcionado à capacitação de profissionais da educação da rede municipal do ensino fundamental de Matinhos, comunidade litorânea do estado do Paraná foi concebido para a ampliação do entendimento destes educadores (as) sobre os conceitos de Ciência e Tecnologia, a partir de uma perspectiva de gênero. O debate com os profissionais da educação como agentes multiplicadores do conhecimento, conscientes de seu papel diante do ambiente escolar, estaria conseqüentemente se estendendo à família e à sociedade. Foi discutida a invisibilidade histórica do feminino na construção do ambiente laboral na área da Ciência e da Tecnologia.
\end{abstract}

Palavras-chave: Gênero; Capacitação; Ciência e Tecnologia; Sexualidade.

\section{ABSTRACT}

The present article deals with the thematic module: Gender, Sexual Diversity, Science and Technology, and it describes the performance of the research groups GETEC - UTFPR - Relations

1 Este artigo foi apresentado originalmente em forma de comunicação, pela Profa. Msc. Tânia Rosa Ferreira Cascaes, no VII Congresso Iberoamericano de Ciência, Tecnologia e Gênero, em Cuba, fev/2008, e contou com modificações na versão para esta publicação.Participaram da elaboração do módulo 3, aqui descrito, além das autoras do artigo, a Profa. Dra.Cristina Tavares da Costa Rocha, Prof. Msc. Benedito Guilherme Falcão de Farias.

2 Mestre em Tecnologia, Socióloga, Especialista em Magistério Superior, Pesquisadora do Grupo de Estudos e Pesquisas em Relações de Gênero e Tecnologia - GETEC/UTFPR. taniarosa@onda.com.br

3 Mestranda em Tecnologia, Membro do Grupo de Estudos e Pesquisas sobre Gênero e Tecnologia - GETEC/UFTPR.Bolsista da CAPES. tatisouza@onda.com.br

4 Doutora em Antropologia Social. Coordenadora do GETEC/UTFPR - Grupo de Estudos e Pesquisas em Relações de Gênero e Tecnologia.mariliagdecarvalho@gmail.com 
of Gender and Technology and REGEDI-UFPR - Relations of Gender and Sexual Diversity. The work, developed by the mentioned groups was aimed at the qualification of professionals of basic education of the urban network of Matinhos, a seacoast community of the state of Paraná. The work was conceived for enhancing the understanding of these educators on the concepts of Science and Technology, from a gender perspective. The discussion with the education professionals as agents of knowledge, conscious of their role in the school environment, would consequently extend itself and reach the family and the society. One of the discussion topics was the historical invisibility of the feminine side in the construction of the labor environment in the area of Science and the Technology.

Key-words; Gender; Teaching; Science and Technology; Sexuality.

\section{INTRODUÇÃO}

Em uma época de intensas mudanças culturais e sociais, onde a flexibilidade do mundo do trabalho substituiu sua antiga rigidez, nos deparamos com um cenário mundial de extremas desigualdades políticas e econômicas.

Significativas são as conseqüências deste contexto para a construção individual das subjetividades contemporâneas e, conseqüentemente, para as relações sociais como um todo.

Diversas são as possibilidades, e lidar com a diversidade torna-se tarefa essencial para o pensamento crítico e transformador.

Entendendo a escola como uma ponte entre os indivíduos e a coletividade, esta se torna um importante agente de mudanças ao promover um maior esclarecimento sobre o sentido desta diversidade, assim como fazer surgir novas práticas como instrumentos efetivos para a construção da cidadania e da justiça social.

Neste sentido, os atuais estudos de gênero se tornam grandes aliados de professores que lidam diretamente com a diversidade em seu cotidiano.

Partindo da construção cultural em torno do gênero e da sexualidade - no que diz respeito às desigualdades hierárquicas entre os atores sociais femininos e masculinos que se manifestam espontaneamente no ambiente escolar em todos os seus níveis, os resultados destes estudos podem promover uma maior sensibilização docente para temas que venham a diminuir os preconceitos que estão dentro e fora dos livros, promovendo assim o surgimento de uma realidade social menos violenta e excludente.

$\mathrm{Na}$ certeza de que a homofobia e incontáveis tipos de preconceitos exercem forte influência no comportamento tradicional das relações sociais, o MEC (Ministério da Educação), por meio da SECAD (Secretaria de Educação Continuada, Alfabetização e Diversidade), instituiu programas que abordam essas questões, na tentativa de esclarecer junto à classe de docentes em todos os níveis, permitindo a elaboração e implementação do projeto intitulado "Refletindo Gênero na Escola:" a Importância de Repensar Conceitos e Preconceitos, direcionado à sensibilização de profissionais da educação, 
da Rede Pública Municipal de Ensino (ensino fundamental), numa comunidade litorânea, Matinhos, localizada no estado do Paraná. Elucidando este estudo, faz-se necessário constar que a comunidade em questão está situada no município de Matinhos, litoral, região de 24.000 habitantes, com o menor IDH do Estado, perfil econômico sazonal, com historia importante de violência de gênero e bullying nas escolas.

$\mathrm{O}$ referido Projeto teve o envolvimento de pesquisadores e pesquisadoras que participam de dois grupos de estudo: GETEC/UFTPR - Relações de Gênero e Tecnologia/Universidade Tecnológica Federal do Paraná e REGEDI/UFPR - Relações de Gênero e Diversidade Sexual/ Universidade Federal do Paraná - setor Litoral.

Assim sendo teve por objetivos ampliar o entendimento e a reflexão dos educadores (as) envolvidos com a questão do "preconceito", que envolve a presença feminina no campo de construção do conhecimento e da prática científica e tecnológica, como também, elucidar no universo da escola essas questões, facilitando ao corpo docente envolvido posicionar-se com argumentos, tendo condições de proporcionar uma educação igualitária e inclusiva, evitando o reflexo negativo da exclusão no mercado de trabalho e conseqüentemente na renda familiar.

Estes objetivos, também, foram elaborados a partir da realidade que se apresenta no cotidiano e cujas reflexões foram elaboradas no intuito de desconstruir paradigmas que se apresentam anacrônicos na percepção da sociedade atual em relação aos sujeitos sociais do masculino e do feminino construído com bases excludentes em relação aos papéis da mulher no cenário público.

Com este intuito assim construímos os objetivos que se seguem:

- Demonstrar a construção histórica e cultural dos conceitos de gênero relacionados ao masculino e ao feminino, destacando a invisibilidade da participação das mulheres no campo da pesquisa e do desenvolvimento científico e tecnológico;

- Através da discussão dos conceitos de ciência e tecnologia, problematizar a questão de gênero no ambiente e nas disciplinas escolares, assim como na pesquisa científica, nas aplicações tecnológicas, na escolha e no exercício das profissões;

- Provocar uma reflexão a respeito da atuação da escola sobre a importância das relações de gênero, ciência e tecnologia.

Segundo a literatura ${ }^{5}$, a invisibilidade histórica do feminino no ambiente laboral nas áreas da Ciência e da Tecnologia, é desde a antigüidade, confundida com conhecimento tácito e aliada ao universo empírico num processo automático de exclusão

5 A literatura consultada teve por objetivo sensibilizar os/as participantes pouco familiarizados com os conceitos de Ciência e Tecnologia utilizados nos meios acadêmicos. Deste modo, utilizamos algumas definições mais "tradicionais" que pudessem ser reexaminadas, ao longo das discussões em grupo, sob a ótica da problemática de gênero. 
das mulheres.

Esta percepção, oculta a presença e a contribuição feminina na produção científica e tecnológica, associa a mulher à pseudociência e constrói estereótipos hierárquicos que se tentou desconstruir mediante os conceitos trabalhados durante o curso.

Na descrição paulatina deste estudo os conteúdos não só exercem, mas enfatizam que a extensão universitária representa uma contribuição importante da comunidade acadêmica para a sociedade como um todo, completando assim, o ensino e a pesquisa. A prática da extensão universitária, neste caso, foi utilizada, também como uma contribuição nas concepções de mudanças sociais e nos processos de inclusão, lacuna percebida na atualidade onde o alcance da mídia reproduz as desigualdades, influenciando o comportamento da sociedade. Segundo Giddens podemos argumentar que "as práticas sociais são constantemente examinadas e reformadas à luz das informações recebidas sobre aquelas próprias práticas, alterando, assim constitutivamente, seu caráter" (GIDDENS,1990, apud HALL, 2003, p.15).

\section{PRÁTICAS METODOLÓGICAS}

No conteúdo do módulo intitulado Gênero, Diversidade Sexual, Ciência e Tecnologia, tema deste artigo, procuramos enfatizar a desconstrução do estereótipo da não participação feminina no mundo do trabalho voltado à Ciência e à Tecnologia, como se essas áreas do conhecimento fossem profissões exclusivas e restritas ao masculino.

O conteúdo foi apresentado de forma a gerar entre os participantes uma discussão dos conceitos de Ciência e Tecnologia, procurando-se resgatar a problemática em relação às questões de gênero e diversidade sexual no ambiente e nas disciplinas escolares, assim como na pesquisa científica, nas aplicações tecnológicas, na escolha e no exercício das profissões.

Também procurou-se demonstrar a construção histórica e cultural dos conceitos de gênero relacionados ao masculino e ao feminino, destacando a invisibilidade da participação das mulheres no campo da pesquisa e do desenvolvimento científíco e tecnológico.

E ainda sensibilizar os participantes em relação à temática de gênero, diversidade sexual, ciência e tecnologia experimentalmente numa comunidade restrita em número de habitantes e provinciana, onde as relações sociais tendem a ocorrer em ambientes onde a convivência social é muitas vezes dificultada pelas ações cotidianas pré-concebidas num convívio social onde os preconceitos geralmente são estendidos a toda a comunidade.

As normas e regras que ditam as práticas culturais nas comunidades menores são 
normalmente voltadas a atitudes androcêntricas por estas serem práticas instituídas subliminarmente em nossa cultura. Com a aplicação e obtenção dos resultados do projeto teríamos base para poder expandi-lo em um contexto maior aonde a aplicação de um trabalho desta natureza e desta dimensão viesse a contribuir com seus resultados na concretização de mudanças sociais.

As metodologias, para o desenvolvimento das aulas foram aquelas que favorecem uma interação participativa do grupo como um todo e também como fonte de avaliação das idéias que eram contempladas pelo próprio grupo.

Iniciar propondo uma dinâmica para trabalhar os conceitos de Ciência e Tecnologia, nos pareceu eficaz, num contexto onde as práticas educativas são incorporadas pelo aprendizado ao longo das experiências de vida e escolares, dos meios de comunicação de massa e outros.

As questões formuladas e respondidas pelos participantes nos deram o grau de assimilação desses conceitos do grupo, ditadas pelo senso comum e pela educação dos mesmos, além dos estereótipos que permeiam normalmente a sociedade, proporcionando assim, o ponto de partida para discussões posteriores.
As perguntas foram:
O que você entende por Ciência?
$\mathrm{O}$ que você entende por Tecnologia?

\section{TRABALHANDO COM OS CONCEITOS}

Os conceitos elaborados e repassados teoricamente ao grupo para este módulo foram baseados em autores consagrados na área da filosofia e da ciência, como Ruy Gama e Milton Vargas, conhecidos pensadores nos estudos da história da técnica e da tecnologia cujas fontes constam nas referências. Notadamente destacamos em uma seqüência as respostas para uma assimilação paulatina destes conceitos, porque o entendimento de termos adotados freqüentemente pela mídia e não assimilados pelos educadores, consiste numa barreira que perpassa o entendimento que não deve se limitar ao que o senso comum adota. Este entendimento contribui para a eliminação das diferenças freqüentemente associadas ao preconceito entre o masculino e o feminino.

Destacamos cronologicamente alguns momentos e autores utilizados, que nos auxiliaram na construção do referencial androcêntrico da Ciência:

Se procuramos saber quem produziu conhecimento nesses 300 anos diremos que (a ciência) é masculina. Muitas mulheres foram, e continuam sendo excluidas da produção da ciência em razão do seu 
sexo. Até hoje, quando as mulheres dominam numericamente alguns campos disciplinares, a imagem de cientista é associada aos homens. De fato as mulheres cientistas raramente ocupam posições centrais na tomada de decisões. ( CITELI, 2000 p.39)

O pensamento dito racional, experimental e neutro (isento de crendices e emoções) promoveu o ocultamento da participação das mulheres neste mundo de objetividade científica. Na produção do conhecimento, comumente tem-se associado a pseudociência ${ }^{6}$ como um campo predominantemente feminino. Desde Francis Bacon, o conhecimento científico na sociedade ocidental tornou-se fonte de autoridade e poder. Se algo é comprovado cientificamente, normalmente é aceito sem muita discussão e passa a regular os pensamentos e as ações dos indivíduos. Geralmente, as diferenças comportamentais entre os sexos são definidas pela ciência de maneira bastante dicotômica, legitimando valores ocultos de dominação e atitudes discriminatórias entre os diversos gêneros. Discutindo a ciência pela ótica das relações de gênero procuramos questionar este paradigma científico buscando uma desconstrução destes conceitos marcados pela desigualdade e exclusão.

A partir de um resgate conceitual histórico da Ciência na sociedade ocidental, procuramos demonstrar que tanto a Ciência quanto a Tecnologia devem ser sempre interpretadas como processos sociais inseridos num contexto histórico, social, cultural, político, econômico, ideológico, religioso, de gênero, dentre outros (CARVALHO, 1998; 2003). Procuramos tornar claro que a Tecnologia assim como a Ciência também foi construída num universo masculino que omitiu a participação das mulheres nestas áreas.

Dentro de uma perspectiva multidisciplinar, a tecnologia passa a ser a base da cultura material moderna e uma condição básica para o desenvolvimento social e econômico de um país.

Assim como a ciência, a tecnologia também possui uma referência androcêntrica. Culturalmente, os homens parecem estar mais à vontade com as inovações tecnológicas, tanto na criação quanto no uso das tecnologias. Afinal desde muito pequenos eles são incentivados a brincar com seus carrinhos, aviões, vídeo games, robôs e outros tantos aparatos eletrônicos.

No entanto, neste mundo cada vez mais informatizado, as mulheres têm superado inúmeros preconceitos e cada dia mais têm provado sua vontade e capacidade de lidar com esta realidade tecnológica no seu dia-a-dia, participando das inovações e indo muito além do mero uso de aparelhos eletrodomésticos.

A Ciência implicava em “descobrir e explicar", era e é sempre baseada em

6 A pseudociência é um tipo de conhecimento que não resulta de métodos rigorosamente científicos. Aceita verdades sem uma evidência experimental. Ex.: psicanálise, astrologia, terapias alternativas (como homeopatia e acupuntura), tarô, magia, adivinhação entre outras. 
observação, razão, experimentação estruturada e revisão de resultados (SILVA, 1998, p. 130). Inicialmente, segundo Descartes, ela consistia numa construção de conhecimento a partir da observação dos fenômenos da natureza através do método.

Por sua vez, a Tecnologia, segundo Gama (1982, p.163) “é o estudo sistemático dos instrumentos, ferramentas, e máquinas e também da utilização dos procedimentos e métodos. Nos diversos ramos da técnica é o estudo científico das operações técnicas e da própria técnica".

É o avanço técnico colocado na prática do trabalho. É a revelação dos mistérios do trabalho, na transmissão do saber-fazer, conseqüentemente produto da prática das relações sociais no trabalho (GAMA, 1982, p.163).

Para Vargas (1994, p.2) tecnologia é conceituada como ciência aplicada e, esta não se compra, se aprende na prática da pesquisa. $\mathrm{O}$ termo tecnociência ${ }^{7}$ não raro é um neologismo e usado como um conceito mais moderno para tecnologia.

Outros autores, como por exemplo, Donna Haraway (1997) e Bruno Latour (2000), pautam suas discussões a partir do conceito de tecnociência que se baseia em relações sociais contemporâneas que integram toda a sua diversidade cultural e técnica.

Assim como HARAWAY, SILVA (1998) argumenta que, dentro de uma perspectiva pós-modernista, a razão já não mais é a detentora exclusiva da construção do conhecimento. Somam-se meios materiais como interface para esta construção.

Discutindo a temática de gênero procuramos questionar este paradigma de referências androcêntricas adotadas pelo método científico tradicional, que repercutiram imensamente no mundo do trabalho, colocando as mulheres no âmbito das profissões do cuidado, e reduzindo suas aptidões àquele do mundo privado. Na crítica às limitações destes conceitos procura-se chamar atenção para superar os preconceitos existentes, construídos nas desigualdades de gênero.

Para ilustrar as relações de gênero no mercado de trabalho que se manifestam desde o período de formação acadêmica, foram utilizadas pesquisas brasileiras recentes (QUADRO I) sobre a participação de homens e mulheres em cursos de graduação, tanto na área das ciências exatas quanto na área de ciências humanas. Foram observadas discrepâncias percentuais que ratificam direcionamentos profissionais sempre ligados à divisão das profissões masculinas e femininas.

7 Tecnociência é um termo cunhado pelo filósofo belga Gilbert Hottois em fins dos anos 70 e usado para designar o contexto social e tecnológico da ciência, considerando sua codificação e posição social, mas com relação direta a redes materiais não humanas. Este conceito também é utilizado por outros autores acima citados, relacionados à contemporaneidade. 


\section{Quadro 1 - PORCENTAGEM DE ALUNOS POR SEXO E POR CURSO}

\begin{tabular}{l|c|c}
\hline Cursos & \% feminina & $\%$ masculina \\
\hline Administração & 49,2 & 50,8 \\
\hline Direito & 48,9 & 51,1 \\
\hline Pedagogia & 91,3 & 8,7 \\
\hline Engenharia & 20,3 & 79,7 \\
\hline Comunicação Social & 56,6 & 43,4 \\
\hline Letras & 80 & 20 \\
\hline Ciências Contábeis & 50,7 & 49,3 \\
\hline Educação Física & 43,1 & 56,9 \\
\hline Enfermagem & 82,9 & 17,1 \\
\hline Ciências da Computação & 18,8 & 81,2 \\
\hline
\end{tabular}

Fonte: Censo da Educação Superior 2006 (Inep/MEC)

Foram utilizadas também, como recurso pedagógico, pesquisas recentes elaboradas e apresentadas por pesquisadores do GETEC - UTFPR- Relações de Gênero e Tecnologia/Universidade Tecnológica Federal do Paraná- sobre a participação de homens e mulheres em cursos de graduação, tanto na área de ciências exatas quanto na de humanas, contendo informações direcionadas às identidades de gênero. Essas pesquisas, em forma de Dissertação de Mestrado foram realizadas recentemente por membros do Grupo Getec- Relações de gênero e Tecnologia - sempre ratificando o que os QUADROS 1 e 2 demonstram da participação feminina nos cursos de Engenharia e dos cursos como um todo.

O QUADRO 1, exemplifica cursos de graduação fortemente marcados por identidades de gênero, como por exemplo, o curso de engenharia com a maior porcentagem de matrículas masculinas e o curso de pedagogia com a maior porcentagem feminina.

Pesquisas de gênero realizadas no curso de engenharia da UTFPR (Campus Curitiba), apontam discrepâncias no número de matrículas do sexo masculino e do sexo feminino. Observando o QUADRO II, nota-se o baixo índice de matrículas do sexo feminino em relação ao índice masculino em todos os anos e em todos os cursos de engenharia. 


\section{Quadro II - DISTRIBUIÇÃO POR GÊNERO DO CORPO DISCENTE DOS}

CURSOS DE ENGENHARIA DA UTFPR, CAMPUS CURITIBA, 1991- 2000.

\begin{tabular}{|c|c|c|c|c|c|c|c|}
\hline \multirow{2}{*}{ Ano } & \multirow{2}{*}{ Sexo } & \multicolumn{4}{|c|}{ Curso } & \multirow{2}{*}{ Total } & \multirow{2}{*}{$\%$} \\
\hline & & Eletrônica & Eletrotécnica & Civil & Mecânica & & \\
\hline \multirow{2}{*}{1991} & $M$ & 72 & 74 & 34 & 0 & 180 & 90 \\
\hline & $\mathrm{F}$ & 8 & 6 & 6 & 0 & 20 & 10 \\
\hline \multirow{2}{*}{1992} & M & 76 & 73 & 25 & 78 & 252 & 90 \\
\hline & $\mathrm{F}$ & 4 & 7 & 15 & 2 & 28 & 10 \\
\hline \multirow{2}{*}{1993} & $\mathrm{M}$ & 74 & 75 & 25 & 78 & 252 & 90 \\
\hline & $\mathrm{F}$ & 6 & 5 & 15 & 2 & 28 & 10 \\
\hline \multirow{2}{*}{1994} & M & 70 & 73 & 28 & 75 & 246 & 87,9 \\
\hline & $\mathrm{F}$ & 10 & 7 & 12 & 5 & 34 & 12,1 \\
\hline \multirow{2}{*}{$1995^{*}$} & $\mathrm{M}$ & 0 & 0 & 0 & 0 & 0 & - \\
\hline & $\mathrm{F}$ & 0 & 0 & 0 & 0 & 0 & - \\
\hline \multirow{2}{*}{1996} & M & 74 & 67 & 27 & 73 & 241 & 86,1 \\
\hline & $\mathrm{F}$ & 6 & 13 & 13 & 7 & 39 & 13,9 \\
\hline \multirow{2}{*}{1997} & $\mathrm{M}$ & 71 & 68 & 27 & 72 & 238 & 85 \\
\hline & $\mathrm{F}$ & 9 & 12 & 13 & 8 & 42 & 15 \\
\hline \multirow{2}{*}{1998} & $M$ & 72 & 72 & 50 & 74 & 268 & 83,8 \\
\hline & $\mathrm{F}$ & 8 & 8 & 30 & 6 & 52 & 16,3 \\
\hline \multirow{2}{*}{1999} & $\mathrm{M}$ & 75 & 70 & 50 & 69 & 264 & 82,5 \\
\hline & $\mathrm{F}$ & 5 & 10 & 30 & 11 & 56 & 17,5 \\
\hline \multirow{2}{*}{2000} & $M$ & 72 & 76 & 53 & 72 & 273 & 85,3 \\
\hline & $\mathrm{F}$ & 8 & 4 & 27 & 8 & 47 & 14,7 \\
\hline
\end{tabular}

Fonte: Comissão de vestibulares, UTFPR, Campus Curitiba - 2004.

* 1995 - Dados não disponíveis neste ano

Dentre as engenharias, a engenharia civil apresentou o maior número de matrículas do sexo feminino, enquanto a engenharia mecânica apresentou a menor presença de mulheres.

Muitos foram os questionamentos realizados a partir destes dados. Por exemplo: quais seriam os motivos para tal discrepância? Quais as dificuldades que as mulheres encontram nos cursos de engenharia? Optamos por selecionar estas perguntas, para trabalhar em forma de interação com os grupos participantes do projeto, pois as evidências que foram encontradas no decorrer das nossas observações, ditadas pelo senso comum, seriam de que a engenharia mecânica, identificada com motores, sugere que 
demanda força física e que seria "coisa de homem", e a engenharia civil teria um número maior da presença feminina, por ter relação com construção de casas, isto é, lares.

\section{A ESCOLHA PROFISSIONAL}

Com base nos dados apresentados, propusemos uma segunda dinâmica onde buscamos novamente na prática o que definiu as escolhas profissionais individuais dos participantes a partir das seguintes questões:

1) O que o (a) levou a escolher sua profissão?

2) Que orientação você daria aos seus(as) alunos (as) quanto à escolha da profissão?

A transcrição de algumas das respostas desta dinâmica possui riqueza de significados atribuídos a valores e experiências pessoais. Assim sendo, os relatos desta segunda dinâmica são bastante expressivos no que diz respeito às experiências vividas pelos participantes.

Dentre as respostas dadas à primeira pergunta, optamos por reproduzir as frases a seguir, pois estas demonstram que a opção determinante para a escolha da profissão tinha como base "fazer por gostar, por vocação" e outras estariam dando prosseguimento à carreira de pessoas com quem conviveram no ambiente doméstico ou no público, quais sejam, as próprias escolas:

- Porque gosto de lidar com crianças, ensinar. Segui a mesma carreira da minha mãe. Acho lindo. Admiro essa profissão.

- Porque desde criança sempre admirei meus professores e isso fez com que eu seguisse essa profissão.

- Porque sempre gostei de cuidar de criança, por isso me identifiquei com a profissão. Comecei trabalhando em creche, fiz o magistério e hoje curso Pedagogia. Tenho 15 anos nessa profissão.

- Gostar da área de ensino desde criança.

- Desde criança eu queria ser professora porque acho até agora a profissão de professora uma das mais belas do mundo.

- Cada vez me identifico mais com o curso de Pedagogia. Nas horas dos estágios sinto-me contagiada pelas crianças. Gosto das aulas, pois sinto que esta seja um laboratório vivo. Adoro aprender e estar em busca de aprender a ensinar.

- Vocação: eu gosto de ensinar e gosto de crianças - ensinar ou trabalhar com 
elas é sempre um ato de troca - eu ensino e aprendo.

- Era um sonho de criança.

No entanto, houve respostas motivadas pela falta de outras opções no mercado de trabalho da região e também como garantia de salário para subsistência.

- A falta de opção de emprego na cidade.

- Por ser um curso que na época tinha campo aqui no município.

- Por falta de opção! Porém hoje gosto.

- A princípio escolhi pedagogia por ser o curso oferecido na cidade.

No que se refere à vocação, foi debatido sobre o que faz as pessoas gostarem de um tipo de atividade e não de outra, assim como foi questionada a legitimidade de uma suposta vocação das mulheres para o ensino.

Sobre a falta de opção apontada, foram acrescentadas às discussões, gênero, as relações de classe e suas possibilidades de interação em prol da transformação social.

Quanto à segunda pergunta, as orientações que dariam para seus/suas alunos/as quanto à escolha da profissão, explicitamos as que se seguem:

- Que eles escolham o que querem ser; mas que tenham opinião própria; não desistir na primeira dificuldade e tem que ver também o dom de cada um.

- Que escolham a profissão que mais se identifiquem e sigam em frente, mesmo se encontrarem algum obstáculo pelo caminho, que não pensem apenas em dinheiro, mas na realização profissional.

- Apoiaria na (sic) escolha dele qualquer que fosse ela.

- Digo a eles que todas as profissões são boas, que o trabalho faz bem ao ser humano, e o que eles escolher (sic) desde que seja trabalho honesto é válido.

- Diria e ele escolher algo que goste de fazer independente do grau de exigência e retorno financeiro. Falaria para ele pensar em algo relacionado com a disciplina que mais gosta na escola sem pensar no status que tem na sociedade.

- Acredito que podemos fazer o que queremos (embora o sistema privilegie desigualdades), então o conselho que tenho para meus alunos é que façam o que desejam, que lutem por mais dificil que seja, quanto mais dura for a batalha melhor será a vitória. Prova viva é a ascensão das mulheres, que antigamente eram mesmo invisiveis, e que hoje, embora em algumas profissões não atuem com igualdade, nem tão invisíveis são ${ }^{8}$.

8 A memória das falas durante as atividades deste módulo, foi feita com a colaboração da Profa. Dra.Cristina Tavares da Costa Rocha. 
Diversas outras afirmações poderiam ainda ser citadas, mas as que estão transcritas dão uma idéia de que, no geral, não se identificam tendências para profissões tidas como mais femininas ou mais masculinas na orientação que estes/as professores/as dariam a seus/suas alunos/as. A reincidência foi com relação a um reforço para um otimismo constante, soando mais como lições de auto-ajuda.

Foi feita apresentação oral, utilizando-se a projeção de imagens que enfatizavam apenas cientistas e filósofos masculinos, como se as descobertas do pensamento e do conhecimento fossem "coisas de homens", ocorrendo uma completa omissão da presença feminina. Apresentou-se neste momento algumas mulheres cientistas, que são relegadas ao esquecimento, mesmo se tratando de Madame Curie e Bertha Lutz.

Foram utilizadas também imagens de cunho pedagógico no ambiente da escola, que seriam interpretadas como tendenciosas no sentido de influenciarem meninos em detrimento das meninas na futura escolha das profissões, a exemplo de sugestões mostrando o universo dos jogos, dos números, das Ciências Exatas as ciências consideradas Hard, enfim, onde só havia meninos.

Apresentamos ainda projeções de imagens de homens e mulheres nas diversas profissões. Algumas eram profissões tidas como histórica e culturalmente apropriadas ao universo masculino, como aquelas aliadas à força física, e outras pertencentes ao universo feminino, identificadas com os cuidados com a casa e com os filhos. Normalmente, as profissões que são direcionadas às mulheres são as do cuidado, aliando-as à maternidade, ao âmbito privado, ao trabalho repetitivo e outras. Por outro lado, às profissões ditas masculinas, geralmente aliam-se figuras de força física, do ambiente público e do pensamento intelectual. Divisão predominante patriarcal androcêntrica da esfera pública e privada aliada às questões de gênero.

\section{CONSIDERAÇÕES FINAIS}

Trabalhar com conceitos de Ciência e Tecnologia através da ótica de gênero apresenta-se tarefa complexa. No entanto, dentro de um contexto social, onde muitas transformações provêm de avanços científicos e tecnológicos, podem trazer contribuições para a promoção de um ambiente escolar menos preconceituoso e que não perpetue relações sociais hierárquicas e discriminatórias.

Entende-se que é necessário alertar e enfatizar aos/às alunos/as a importância da escola e dos professores/as para a escolha da profissão dos/as futuros/as trabalhadores/as da comunidade apresentada; a necessidade de uma reflexão pela desconstrução de idéias pré-concebidas de que Ciências Humanas x Exatas seriam relativas às meninas e aos meninos respectivamente. Parte-se do princípio de que não só as meninas podem ser incentivadas a optar pelas Ciências Exatas, mas igualmente os meninos podem ser 
estimulados a optar pelas Ciências Humanas, como magistério, pré-escola, artes, e outras.

Em síntese, a diversidade de gênero no mundo do trabalho, além de enriquecer as relações sociais significa troca e encadeamento de idéias, sugestões, discussões, maneiras de resolver problemas. Contribui também para que o número de vagas profissionais em determinados segmentos, anteriormente essencialmente masculinos poderá abrir espaço para mulheres. Estas transformações poderiam contribuir para aumentar o orçamento de uma família, por exemplo, cujas escolhas poderiam ser mais diversificadas, aumentando, numa visão macroeconômica, a distribuição de renda.

Os resultados deste módulo evidenciaram que cursos de extensão universitária auxiliam na compreensão dos processos de mudanças sociais e nos processos de inclusão como um todo. Referenciaram a importância de levar para o maior número de educadores a necessidade de repensar os padrões tradicionais de gênero no âmbito da ciência e da tecnologia que têm se revelado preconceituosos e discriminatórios no ambiente escolar e, conseqüentemente, na sociedade em geral.

Contribuem também para divulgar aos educadores informações no sentido de sensibilizá-los para a construção histórica do conhecimento, além de problematizar a temática, promovendo reflexões oportunas, visando mudanças em comportamentos na prática social cotidiana. A ênfase no reconhecimento da diversidade que existe entre as pessoas e que elas têm o direito de se manifestar sem ser violentadas, seja esta violência simbólica ou física, oculta ou aparente, contribui para a justiça social, onde a solidariedade, que poderia ser a marca constituinte da sociedade moderna, possa se manifestar integralmente.

\section{REFERÊNCIAS}

CARVALHO, Marília G. Tecnologia e sociedade. In: BASTOS, J.A.L.A. (Org.). Tecnología e interação. Coletânea Educação e Tecnologia. Curitiba: Ed.CEFET-PR, 1998.

CARVALHO, Marília G. Relações de gênero e tecnologia: Uma abordagem teórica. In: CARVALHO, M.G. (Org.). Relações de Gênero \& Tecnologia_Coletânea Educação e Sociedade. Curitiba: Editora CEFET-PR, 2003.

CITELI, Maria Tereza. Mulheres nas ciências mapeando campos de estudos. Cadernos Pagu, Campinas, v.15, 2000

GAMA, Ruy. História da técnica e da tecnologia. São Paulo: EDUSP, 1985

GAMA, Ruy. Engenho e tecnologia. São Paulo: Duas Cidades, 1983.

HALL, Stuart. A identidade cultural na pós-modernidade. 7.ed. Rio de Janeiro: DP\& A, 2003

HARAWAY, Donna Jeanne. Modest Witness@Second Millennium.

FemaleMan®C_Meets_OncoMouse ${ }^{\mathrm{TM}}$ : Feminism and Technoscience. New York: Routledge, 1997.

LATOUR, Bruno. Ciência em ação: Como seguir cientistas e engenheiros sociedade afora. Tradução de Ivone C. Benedetti. São Paulo: UNESP, 2000. 
SILVA, Elizabeth Bortolaia. Des-construindo gênero em ciência e tecnologia. In: Cadernos pagu (10) 1998, p. 7-20.

VARGAS, Milton. História da técnica e da tecnologia. São Paulo: UNESP, 1994.

VARGAS, Milton. Para uma filosofia da tecnologia. São Paulo: Alpha Omega, 1994. V.5. 